\title{
O MITO, O MÉTODO E A HISTÓRIA: A REVOLUÇÃO RUSSA SOB A ÓTICA DE MAURÍCIO TRAGTENBERG
}

\author{
DORIS ACCIOLY E SILVA* \\ LUCIA BRUNO**
}

\begin{abstract}
RESUMO: O presente artigo aborda aspectos relevantes do texto de Maurício Tragtenberg, intitulado "Rússia atual: produto da herança bizantina e do espírito técnico norte-americano" (1954). Busca-se aqui evidenciar a originalidade da análise do autor sobre as afinidades entre o poder soviético e o norte-americano e sobre os profundos processos históricos e simbólicos subjacentes à Revolução Bolchevique de 1917. Destacam-se a radicalidade da crítica de Maurício Tragtenberg aos dois centros do poder mundial na época e a importância dessa crítica não só no ambiente da esquerda brasileira da década de 1950, mas dentro do debate político contemporâneo.
\end{abstract}

Palavras-chave: Crítica. Revolução Bolchevique. Poder. Tecnicismo. Mito.

\section{Myth, METHOD AND history: the Russian ReVolution through the eyes of Maurício Tragtenberg}

ABSTRACT: This paper approaches relevant aspects of Mauricio Tragtenberg's text: Present Russia: product of Byzantine heritage and of the North-American technical spirit (1954). The point is to evince the originality of Tragtenberg's analysis of the affinities between Soviet and North-American powers and of the deep historical and symbolical processes underlying the 1917 Bolshevik Revolution. Emphasis is given to the radicality of the author's critique of the two

* Doutora em Sociologia e professora do Departamento de Administração Escolar e Economia da Educação da Universidade de São Paulo (USP). E-mail: daccioly@usp.br

** Doutora em Sociologia e professora do Departamento de Administração Escolar e Economia da Educação da Usp. E-mail: lenuevo@usp.br 
worldwide centers of power of that time and to the importance of this critique not only for the Brazilian leftist milieu in the 1950s, but also within the contemporary political debate.

Key words: Critique. Bolshevik Revolution. Power. Technicism. Myth.

artigo de Maurício Tragtenberg publicado neste número apareceu na Folha Socialista, ${ }^{1}$ em abril de 1954, jornal do Partido Socialista Brasileiro, do qual faziam parte Antonio Candido, Phébus Gikovate, Arnaldo Pedroso D'Horta, Paul Singer, entre outros. Trata-se de artigo praticamente desconhecido e esta é uma das razões de divulgálo neste momento em que se completam 10 anos de sua morte. Primeiramente, gostaríamos de chamar a atenção do leitor para a originalidade da análise de Tragtenberg acerca da chamada Rússia Soviética, considerando o debate da esquerda brasileira na época em que foi escrito. Além disso, cabe ressaltar que nesse artigo encontram-se já explicitados alguns elementos centrais da formação do autor e de seu pensamento político, como poderão reconhecer os leitores de sua obra. Vale, igualmente, referir a importância conferida por Tragtenberg aos processos simbólicos ${ }^{2}$ para a compreensão da vida social e para o desvendamento dos processos ideológicos e, finalmente, assinalar a atualidade que esse artigo guarda frente aos dilemas da política contemporânea.

A análise da situação russa no contexto da esquerda brasileira

Estávamos em 1954, quando, após o final da Segunda Guerra Mundial, o mundo se dividira em dois grandes blocos subordinados a dois centros de poder: o russo e o norte-americano. O debate no Brasil, no campo da esquerda, de modo algum contemplava uma crítica tão radical quanto a que Tragtenberg aqui apresenta ao processo de consolidação do regime instaurado na Rússia pelos bolcheviques e muito menos estabelecia relaçôes entre esses dois eixos de poder: o russo e o norte-americano.

No panorama da esquerda, predominavam as teses da III e da IV Internacionais. A crítica à Revolução Russa e aos seus desdobramentos subordinava-se, no caso dos trotskistas, aos enfrentamentos com os stalinistas, embate que já assumira contornos dramáticos durante a Guerra 
Civil na Espanha (1936-1939). Os trotskistas dirigiam sua crítica, sobretudo, ao modo pelo qual o stalinismo se valia da burocracia, sem, no entanto, questioná-la como forma de dominação, como já fora desvendada pelo liberal Max Weber. Ou seja, a burocracia não era um problema em si, da mesma forma que não se criticava o regime político e social saído da revolução de outubro, que, desde 1917 até a morte de Lênin em 1924, contou com a participação ativa de Trotsky. Da mesma forma, não colocavam em dúvida que a URSS era socialista. Esta limitação da crítica trotskista mantinha em relativa invisibilidade o papel fundamental dos gestores ou burocratas como nova classe dominante, amparada no controle do Estado e do aparelho produtivo. Ainda que fossem contrários à idéia, defendida por Stálin, do "Socialismo em um só país” e defendessem o internacionalismo dos processos revolucionários, não questionavam a estrutura de poder que se consolidou na Rússia pós 1917, fundada no poder da burocracia do Partido e na propriedade estatal dos meios de produção.

Quanto aos socialistas, fiéis às concepções da II Internacional, especialmente na sua vertente parlamentarista e legalista, a crítica incidia, principalmente no caráter autoritário e despótico do stalinismo, sem, contudo, questionar a permanência da separação entre governantes e governados no país da revolução proletária.

A crítica anarquista, por sua vez, iniciada já nos primeiros anos da Revolução Russa, tendo como base os massacres dos marinheiros de Kronstadt, do exército popular de Nestor Mackno (que tão importante fora na luta contra o "exército branco"), e a destruição dos soviets pela ação do partido bolchevique, foi fundo na questão da organização e exercício do poder no novo regime que se afirmava. Embora tivesse ampla divulgação nos meios operários, a crítica anarquista foi praticamente silenciada, a partir dos anos de 1930, em decorrência dos reveses que sofreu graças à repressão violenta do Estado, sem nos esquecermos da hegemonia do Partido Comunista e dos trotskistas. Dessa forma, quando Tragtenberg publica esse artigo na Folha Socialista, em 1954, sua análise, ainda que singular e ousada, abriga muitos elementos da crítica anarquista acima mencionada, à medida que vai diretamente ao cerne da questão: a lógica e as características assumidas pelo novo Estado na União Soviética, tendo como referência básica as relações deste com o proletariado. $\mathrm{Na}$ realidade, considerando que Tragtenberg era freqüentador dos 
Centros de Cultura Social, organizados pelos anarquistas de São Paulo, compreende-se essa reverberação.

No entanto, Tragtenberg aporta outra dimensão à análise do processo russo, recorrendo à história. Nessa perspectiva, vai encontrar no passado bizantino da Rússia, no seu entrelaçamento com os desdobramentos da Revolução e, principalmente, com o bolchevismo, as forças determinantes da configuração que assumiu até a segunda metade do século $\mathrm{xx}$, quando o artigo aqui examinado foi escrito.

Entrelaçamento da história e dos processos simbólicos como recurso de análise da realidade social

No conjunto da obra de Tragtenberg, o recurso à história é permanente e, nesse texto, pode-se perceber como ele a entrelaça aos processos simbólicos, situando-os na esfera das práticas sociais vividas.

Utilizando uma linguagem metafórica, que aqui é também procedimento heurístico, traz da geologia a figura da pseudo-morfose. De acordo com o Glossário Geológico (1977, p. 152), a pseudo-morfose mineral indica "um corpo, cuja forma externa corresponde à do cristal original, mas, no entanto, é constituído por material neo-formado, como, por exemplo, a pirita limonitizada, ou a calcita substituída pelo quartzo etc.".

Em termos históricos, segundo Tragtenberg, a pseudo-morfose se dá "quando uma cultura estranha cai sobre outra com tanta força que a cultura jovem não consegue respirar livremente, não chegando a constituir-se nas suas formas expressivas e peculiares, com consciência de seu papel histórico". Observe-se que, para o autor, trata-se de uma relação de poder em que conquistadores e/ou aspirantes à nova classe dominante se impõem como lavas vulcânicas, imiscuindo-se nas cavidades dos processos históricos, impedindo ou absorvendo a emergência do novo.

Como bom leitor de Cassirer e de Marx, Tragtenberg não ignora a importância da dimensão simbólica nos processos históricos. Vale lembrar a análise, tão cara a ele, que o autor de O Mito do Estado realizou, nos anos de 1930, a respeito da utilização dos mitos germânicos pelos nazistas, numa verdadeira pseudo-morfose. 
No caso do cristianismo, abordado por Tragtenberg logo no início do artigo, a pseudo-morfose manifesta-se no mito do nascimento de Jesus, cuja origem é imemorial. Esse mito já aparece, como nos diz Walker (1983, p. 464), "no livro de Enoch, do século II a.C., em que Yeshua ou Jesus era o nome secreto dado por Deus ao Filho do Homem; título persa que significava "yaweh salva". Outra referência mítica trazida por Tragtenberg é a de Saoshyant: o salvador do mundo na escatologia do zoroastrismo, também chamado de mazdaísmo. O zoroastrismo chegou a ser religião dominante de uma parte expressiva do Grande Irã, influenciando a história e as tradições dessa região. A conquista islâmica, no entanto, marginalizou o zoroastrismo a partir da metade do século VII. Hoje, calcula-se que há menos de 20 mil adeptos na região, sendo que a Índia concentra o maior número deles, chegando a 70 mil (idem, ibid.).

Quanto à lenda da Virgem Maria, Walker, estudiosa das mitologias antigas, refere-se ao mito do Salvador persa Mani, que teria sido gerado por uma deusa virgem chamada Mar, Mariam. Fundador da seita dos maniqueus, Mani era tido, no século III d.C., como outra encarnação do Cristo e sua mãe era chamada de "mãe da vida do mundo inteiro".

Os cistercienses, por sua vez, no século XIII, se autodenominavam “cavaleiros de Nossa Senhora”, associando-a à divindade pagã May Queen (idem, ibid.).

De todos os atributos herdados das deusas pagãs, a virgindade de Maria foi o mais enfatizado pelo cristianismo. Segundo esta autora, "Maria era chamada de $A$ Virgem e não de $A$ Mãe. O êxito da amputação da sua sexualidade pré-cristã evidencia-se nas lendas marianas, que insistiam em afirmar que, embora espantosamente bela, nenhum homem jamais a olhara com desejo" (idem, ibid., p. 610-611).

É exatamente esse processo de desfiguração de mitos pagãos pelas várias vertentes do cristianismo que Tragtenberg denomina pseudomorfose, destacando o processo no qual Cristhus se converte no nome do Salvador e no título de Jesus, salientando que estes títulos já eram vinculados ao culto helenístico do Imperador. Ou seja, no período em que vigorou o domínio macedônico, a idéia do Senhor Salvador já expressava a figura de um poder centralizado e sacralizado. 
As lendas bilinas, às quais se refere Tragtenberg em sua análise, eram narrativas épicas transmitidas oralmente a partir do século $\mathrm{X}$, ou até mesmo antes. Foram classificadas em vários grupos, sendo o maior deles ligado à época de ouro de Kiev, quando essa cidade era a capital da Rússia, nos tempos do príncipe Vladimir, ${ }^{3}$ entre os séculos X e XII. Consideradas em seu conjunto, elas constituem uma história folclórica, muitas vezes como variante da história oficial. As bilinas mais conhecidas pelos pesquisadores nasceram das lendas camponesas, cantadas por homens e mulheres, e refletem a necessidade de criação de heróis com força sobre-humana, heróis nativos sempre em luta com os inimigos das estepes. Como se sabe, a tradição oral sempre comportou uma recriação permanente conforme os atores que narram as histórias, sempre acompanhadas por um instrumento de corda e, modernamente, faladas ou cantadas. Os heróis mais antigos surgem assim, conectados a mitos arcaicos, como é o caso de Ilya Muromets, ao qual Tragtenberg faz referência.

Cabe lembrar que a sacralização do poder por meio dos cristianismos ocorreu não só na Rússia bizantina, mas em grande parte do mundo ocidental. Basta considerar a instrumentalização dos mitos que, após processos análogos aos referidos por Tragtenberg na sua análise, sustentaram o regime senhorial nas regiōes da Europa em que este regime existiu. Desde os reis taumaturgos até a legitimação do poder real pelo papado, evidencia-se a estreita relação entre exercício do poder monocrático e processos simbólicos que operam um deslocamento de sentido de mitos originais.

No caso da análise do sistema de poder instaurado pelos bolcheviques, Tragtenberg vai apresentá-lo como resultante da pseudomorfose decorrente da tradição bizantina e do espírito técnico do capitalismo norte-americano.

Um elemento da tradição bizantina, que se encontra na própria estrutura do Império Teocrático Russo, reaparece na estrutura de poder que se consolida já nos primeiros anos da Revolução, com a fusão entre o partido bolchevique e o Estado recém-conquistado, dirigido por um líder carismático, cultuado como o Grande Salvador - Lênin. Como escreve Tragtenberg em seu artigo, o "edifício totalitário moscovita teve sua fachada mudada duas vezes - sob Pedro o Grande e Lenine, mas a essência de sua estrutura conservou-se inalterada". Trata-se de colocar 
em evidência a permanência de uma lógica que continua a modelar a estrutura do poder e o seu exercício na Rússia pós-revolução e cuja origem remonta à época em que o principado de Moscou, convertido no centro do reagrupamento da cristandade ortodoxa russa, na luta contra os muçulmanos e latinos, tomou dos gregos a herança bizantina, processo este que prosseguiu com Ivan - o Terrível que se fez coroar Tzar em 1547, proclamando-se Imperador Romano do Império do Oriente.

O outro elemento da pseudo-morfose da qual resulta o bolchevismo é, segundo Tragtenberg, a assimilação "da técnica ocidental, mais precisamente, do espírito técnico norte-americano", pelos dirigentes do Estado soviético. Esta assimilação é de tal ordem que nem mesmo Maiakovsky ficou imune a ela, como podemos observar no poema desse autor, transcrito por Tragtenberg em seu artigo.

Embora menos entusiasta que Marinetti, na Itália, exemplo extremado do fascínio exercido sobre muitos pelo "espírito técnico norte-americano", cantando em versos e em seu famoso Manifesto, uma verdadeira ode à velocidade alucinante da máquina, à violência engendrada pela sociedade industrial e pelas guerras modernas, Maiakovsky, ainda assim, não parece ter percebido o que se desenvolvia nos subterrâneos desse novo mundo. Ou seja, como já dissera Weber e Tragtenberg o corroborava (1976), o desencantamento do mundo carregava uma profunda ambigüidade, pois os processos de racionalização e secularização tanto nos libertavam de superstições, quanto produziam uma nova escravidão, qual seja, a do homem sob os ditames da dominação burocrática.

Lênin, ao contrário, com a lucidez que o caracterizava, bem cedo percebeu as potencialidades políticas do modo de organização do trabalho e da sociedade que se desenvolvia nos Estados Unidos, em moldes muito mais elaborados do que nos velhos países europeus que tinham engendrado a Revolução Industrial há muito mais tempo.

Em seu texto "As tarefas imediatas do poder bolchevique", publicado em 1918, Lênin faz a defesa do taylorismo e apresenta as medidas a serem adotadas quanto à nova organização do trabalho. Entre as medidas anunciadas, constava a introdução de um sistema de controle da produtividade de cada operário, a adoção de regulamentos de fábricas elaborados pelas direções e a premiação de trabalhadores que 
O mito, o método e a história: a Revolução Russa sob a ótica de Maurício Tragtenberg

alcançassem índices mais altos de produtividade (Bruno, 1976). Dirigindo-se aos revolucionários que criticavam essas medidas, Lênin (1960, p. 702-704) escreveu:

(...) somente os representantes da indecisão pequeno-burguesa vêem no último decreto sobre a administração das estradas de ferro, que concedeu poderes ditatoriais (ou ilimitados) a determinados dirigentes (...) a negação dos princípios da direção coletiva, da democracia e dos princípios do Poder Soviético. (...). A máquina industrial em larga escala, que é fonte da produção material e a base do socialismo, exige uma estrita e absoluta unidade de vontade que dirija o trabalho comum de centenas e dezenas de milhares de pessoas (...). Porém, como assegurá-la? Subordinando a vontade de milhares à vontade de um só (...). A subordinação incondicional a uma única vontade é absolutamente necessária para o bom êxito dos processos de trabalho. [Grifos de Lênin]

Na mesma perspectiva, Trotsky proclamou no IX Congresso do Partido Bolchevique em 1920:

Não se pode deixar a classe trabalhadora a vagabundear através da Rússia (...). Devem ser colocados aqui e ali, ordenados, comandados, exatamente como soldados (...). O trabalho obrigatório atingirá o seu Zênite durante a transição do capitalismo para o socialismo (...). Os desertores do trabalho devem ser reunidos em batalhões punitivos ou postos em campos de concentração. (Brinton, 1975, p. 152)

Assim, pode-se compreender melhor a análise de Tragtenberg acerca da revolução de 1917, em que esta é vista como a síntese lógica de dois processos: o da herança estatal totalitária do Bizâncio e o processo de assimilação do totalitarismo do capital, na sua vertente norteamericana, que, não por acaso, fascinava a nova classe dominante que assumiu o poder depois do assalto ao Palácio de Inverno, em 1917.

Essa perspectiva de Tragtenberg, elaborada em 1954, reaparece em análises posteriores de forma mais sutil, quando critica o capitalismo de Estado existente na Rússia. Em artigo publicado na Folha de S. Paulo, em 8/11/1977, ele mostra como Stálin buscava dar legitimidade à sua política do "socialismo em um só país", recorrendo à tradição e às batalhas do exército russo ocorridas antes da revolução. Cita trechos de um discurso de Stálin, proferido em 1941, no $24^{\circ}$ aniversário da revolução de 1917, onde são exaltados santos da Igreja Ortodoxa e 
"figuras másculas de nossos antepassados" (como os referiu Stálin), no caso, um deles era o Marechal Suvorov, que lutou contra a Revolução Francesa e reprimiu a rebeliāo camponesa de Pugatchev. Esta forma de legitimação do poder vinculava-se, segundo Tragtenberg, a um messianismo nacional que vinha de longe.

Finalmente, gostaríamos de assinalar a atualidade da análise apresentada, no texto aqui publicado, e a propriedade da metáfora da pseudo-morfose para a compreensão de certos processos sociais contemporâneos. Referimo-nos ao caso da China atual, em que o Estado começa a reabilitar aspectos do Budismo na sua vertente mais conservadora, exaltando-se os ideais de harmonia, tolerância e consenso social, além da revitalização de uma mística da passividade. Hoje, os slogans marxistas-leninistas já não mobilizam a população e pertencer ao partido é, para muitos, sinônimo de carreirismo e de corrupção. Assim, o governo chinês se apressa em restabelecer relaçôes diplomáticas com o Vaticano e a reabilitar antigas religiões até há pouco tempo proscritas pelo regime. Muitos jovens estão sendo empurrados para o Budismo, sobretudo estudantes das zonas urbanas e das classes médias. No momento, o Estado é cada vez mais tolerante com a proliferação de templos e outros lugares de culto, tendo em vista administrar os conflitos latentes na sociedade chinesa e prevenir-se contra novas ondas de protestos, tais como as ocorridas nos últimos anos. Não por acaso, em $1^{\circ}$ de outubro de 2007, pouco depois do XVII Congresso do Partido Comunista, o governo chinês colocou em órbita um satélite, cujo nome é Chang'e, conhecida deusa budista. (Hsuan-Wou \& Reeve, 2008).

Este processo ocorre simultaneamente à assimilação, pelos donos do poder na China, do "espírito técnico do capitalismo ocidental", em que os limites da exploração só podem ser estabelecidos pelas lutas dos trabalhadores na defesa de seus direitos e de suas vidas. Para evitar o enfrentamento com os trabalhadores, as ideologias forjadas pelo poder de Estado chinês, a partir de slogans marxistas, já não se sustentam. Para além da repressão que encontra sempre seus limites no risco de deflagrar lutas generalizadas e incontroláveis, que poriam em risco todo o projeto capitalista da Grande China, há que se recorrer também aos processos simbólicos que buscam resgatar os elementos mais conservadores e até mesmo reacionários de antigas religiōes. Resta saber se essa harmonia precária, buscada através da instrumentalização do budismo e de outras construções simbólicas, se sustentará. 
Na Rússia atual, vemos que a herança bizantina, no que tem de autocrática, messiânica e centralizadora, continua a ser evocada por Putin e seus seguidores. O mito da Grande Rússia não desapareceu, ao contrário, parece sustentar seus projetos expansionistas e centralizadores. Nova pseudo-morfose? Quais elementos estão ali sendo acomodados lado a lado, quais lavas vulcânicas, como diz Tragtenberg em seu artigo, estão a ocupar as cavidades abertas pelo processo de mudanças pelo qual passa a sociedade russa?

Recebido em outubro de 2008 e aprovado em novembro de 2008.

\section{Notas}

1. O jornal Folha Socialista existiu de 1946 até 1964.

2. Agradecemos as indicações bibliográficas de Lucia Fabrini de Almeida relativas aos estudos sobre símbolos, mitos e lendas.

3. Wladimir reinou entre 980-1015 e era casado com Ana, irmã do Imperador bizantino. Estabeleceu a ortodoxia como religião do Estado da Rússia, situação que permaneceu até 1917.

\section{Referências}

BAILEY, J.; IVANOVA, T. An anthology of Russian folk epics. Nova York: Sharp, 1999.

BRINTON, M. Os bolcheviques e o controle operário. Porto: Afrontamento, 1975.

BRUNO, L. Gestores: a prática de uma classe no vácuo de uma teoria. In: Bruno, L.; SACCARdo, C. Organização, trabalho e tecnologia. São Paulo: Atlas, 1976.

HSUAN-WOU, H.; REEVE, C. China blues. Paris: Verticales; Phase Deux, 2008

LEINZ, V.; LEONARDOS, O.H. Glossário geológico. São Paulo: Nacional, 1977.

LENIN, W. Obras escogidas. Moscou: Moscou, 1960. 
TRAGTENBERG, M. Max Weber e a Revolução Russa. Estudos CEBRAP, São Paulo, n. 18, p. 47-70, 1976.

TRAGTENBERG, M. De Lênin ao capitalismo de Estado; parte I. Folha de S. Paulo, São Paulo, 6 nov. 1977. Caderno Exterior, p. 18. TRAGTENBERG, M. De Lênin ao capitalismo de Estado; parte II. Folha de S. Paulo, São Paulo, 8 nov. 1977. Caderno Exterior, p. 10. TRAgTenberg, M. A Revolução Russa. São Paulo: unesp, 2007. WALKER, B.G. Woman's encyclopedia of myths and secrets. New York: Harper, 1983. 